\title{
VALIDAÇÃO DO MODELO DE MISTURA DE AÇOS DO LINGOTAMENTO DE PLACAS APLICADO À LAMINAÇÃO DE CHAPAS GROSSAS*
}

\author{
Afranio Marcio Costa ${ }^{1}$ \\ Carlos Vinicius Domingos de Carvalho ${ }^{1}$ \\ Fernando Isac de Melo Miranda ${ }^{2}$ \\ Maik Valentim Venâncio ${ }^{2}$ \\ Thais de Lima Barreto ${ }^{2}$ \\ Victor Assis de Souza Santos ${ }^{3}$
}

\section{Resumo}

No lingotamento contínuo a busca pelo aumento de produtividade tem sido realizada com sequências longas, ou seja, várias corridas e muitas vezes com aços de diferentes composições químicas. Isso resulta na geração de placas de mistura e vários trabalhos buscam entender este processo. Este estudo tem como objetivo validar o modelo matemático de mistura existe no lingotamento da Gerdau Ouro Branco para garantir a correta aplicação da região de mistura, visando atender às especificações dos produtos, norma ASTM A36. Os resultados encontrados nas placas amostradas confirmaram a eficiência do modelo para estimar a zona de mistura. Além disso, para garantir a aplicação dessas placas na norma estudada foi utilizado o modelo de previsibilidade de propriedades mecânicas existente na laminação de chapas grossas. Finalmente, os resultados reais de composição química, limite de escoamento e resistência encontrados nas chapas avaliadas confirmaram as previsões dos modelos e atenderam às especificações do aço.

Palavras-chave: Modelo de mistura; Lingotamento de placas; Chapas grossas.

\begin{abstract}
SLAB CASTING VALIDATION MIX STEEL APPLY IN PLATE MILL
Abstract

Currently the big challenge for steelworks is the increase the productivity. In continuous caster this is achieve by long sequence with several heats and often with different chemical composition but this promote many intermix slabs. This paper objective is check to the mix mathematical model in the slab continuous caster of Gerdau Ouro Branco to ensure that remove the correct slab mix length to guarantee the product specification. The slabs chemical composition results confirmed that the mix model calculation is correct to estimate the intermix zone. In addition, to ensure the application of these slabs in the ASTM A36, the plate mill mechanical properties predictability model used. Finally, the chemical composition, yield and resistance limits in the plates evaluated confirmed the models predictions and met the standard specification.
\end{abstract}

Keywords: Mix model; Slab casting; Plate mill.

1 Engenheiro Metalurgista, Especialista de Aciaria, Ouro Branco, Minas Gerais, Brasil.

2 Estudante de Engenharia Metalúrgica IFMG, Estagiário Universitário, Ouro Branco, Minas Gerais, Brasil.

3 Estudante de Engenharia Metalúrgica UFOP, Estagiário Universitário, Ouro Branco, Minas Gerais, Brasil. 


\section{INTRODUÇÃO}

O aumento na eficiência de produção do lingotamento contínuo de placas exige a produção em sequências longas, várias corridas, sem que seja necessário parar e reiniciar o lingotamento. Assim como uma maior variedade de aços precisam ser produzidos, a mistura de diferentes graus de aço tem se tornado um problema para as siderúrgicas. Os produtores de aço precisam conhecer os pontos exatos de início e fim da região de transição entre aços, para que o corte dessa parte seja efetuado visando garantir as especificações do produto e a satisfação dos clientes.

$\mathrm{Na}$ Gerdau Ouro Branco este problema tem se tornado significativo principalmente após a entrada em operação das laminações de planos, produção de bobinas e chapas grossas. Com o aumento do portfólio de produtos nessas linhas, tornou-se necessário a produção de diversos aços com diferentes composições químicas. Como essa produção é realizada em uma máquina de placas, torna-se necessário a realização do "mix steel", para não afetar o volume total de produção na Aciaria.

O comprimento da faixa de transição entre os aços depende da diferença entre as duas composições químicas. Vários autores[1, 2, 3, 4] dividem essa faixa em duas partes, uma relacionada à mistura no distribuidor e outra no veio.

Segundo Alizadeh et al[2], os parâmetros que influenciam diretamente no comprimento da mistura são:

$\checkmark$ Volume de aço líquido remanescente no distribuidor durante a abertura da nova panela;

$\checkmark$ Velocidade de lingotamento durante a troca de aço;

$\checkmark$ Dimensão do produto lingotado (largura e espessura);

$\checkmark$ Taxa de enchimento do distribuidor com o novo aço;

$\checkmark$ Geometria e mobiliário interno do distribuidor (barragens, diques, inibidor de turbulência); e

$\checkmark$ Composições químicas do aço anterior e posterior a troca de panela.

Em vários trabalhos publicados $[1,2,3,4]$ menciona-se que a maior contribuição do volume de mistura está relacionada com o escoamento do aço no distribuidor. Para diminuir a região de mistura, o escoamento do tipo pistonado deve ser maximizado enquanto o volume morto deve ser minimizado [5,6]. A figura 1[1] ilustra o fluxo de aço no distribuidor apresentando os diferentes padrões e volumes de escoamento existentes.

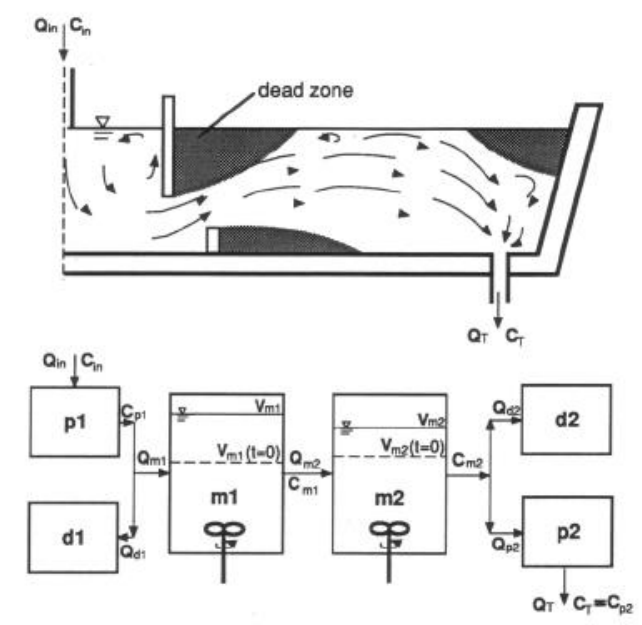

Figura 1. Desenho esquemático do distribuidor mostrando os padrões de fluxo (HUANG, 1996). Além dos regimes de fluxo do aço dentro do distribuidor, a taxa de enchimento durante a troca de panela é fundamental para otimizar a região de mistura. Goldschmit et al 
[3] avaliaram diferente condições de alimentação do aço visando maximizar a troca de aço dentro do distribuidor. A figura 2 apresenta as duas condições estudadas.

a)

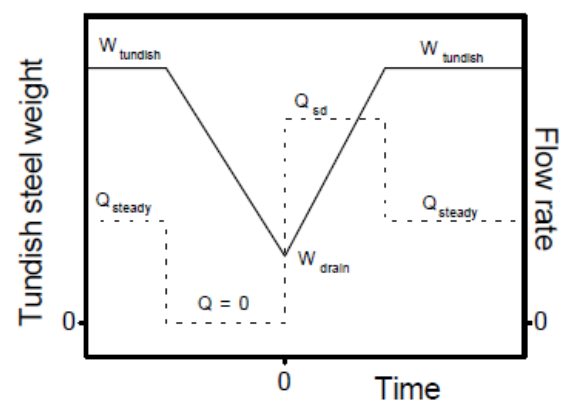

b)

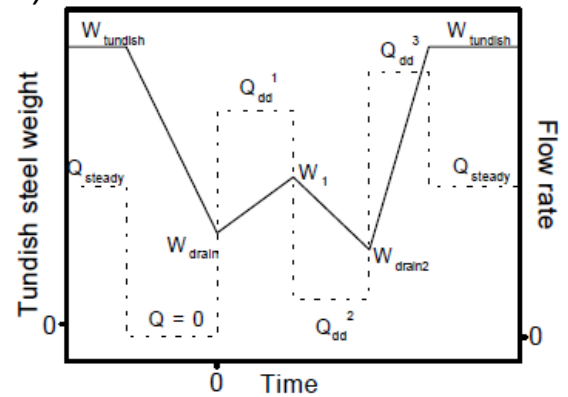

Figura 2. Diferentes padrões de enchimento do distribuidor: a) taxa enchimento constante; b) taxa de enchimento variável (GOLDSCHIMIT, 2000).

Os resultados encontrados [3] mostram que o padrão de enchimento com taxa variável é mais eficiente para reduzir o volume de mistura gerada no distribuidor.

$O$ efeito da mistura no veio também tem sido estudado[1,2,3] e, em geral, pode ser dividido em duas regiões. A primeira está relacionada ao escoamento no molde devido ao fluxo de aço pela válvula submersa e tem uma forte componente turbulenta. A segunda região é regida pela difusão do aço dentro do veio durante o processo de solidificação. Em alguns estudos essa contribuição pode ser desprezada [5,6].
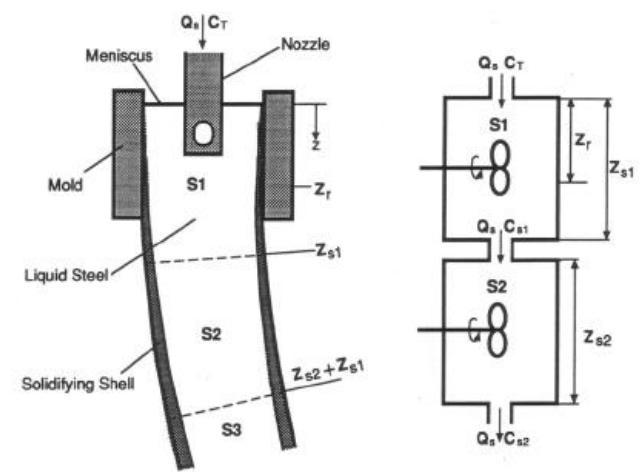

Figura 3. Esquema de modelamento do mix steel no veio (HUANG, 1996).

Para evitar a mistura no veio pode-se adotar a prática de uso de uma chapa separadora, que é introduzida dentro do molde no momento da troca de aço. Isso garante que não há perda por mistura relativa ao veio.

Outra opção é realizar a troca do distribuidor. Neste caso a perda por mistura é reduzida drasticamente.

Na Gerdau Ouro Branco utiliza-se um modelo de mistura no lingotamento de placas que leva em consideração os parâmetros de processo apresentados anteriormente que são: velocidade de lingotamento, peso de aço no distribuidor, dimensões da placa, taxa de enchimento do distribuidor e designer do distribuidor.

O presente trabalho foi desenvolvido tendo como principais objetivos:

$\checkmark$ Validação do modelo matemático de formação de placas de misturas no lingotamento contínuo de placas,

$\checkmark$ Validação do modelo de previsão de propriedades mecânicas existente na laminação de chapas grossas utilizando as placas de mistura, e 
$\checkmark$ Confrontar as propriedades mecânicas das chapas grossas laminadas, a partir das placas de mistura, com as especificações do aço estudado.

Em alguns casos essas placas são descartadas e em outros elas podem ser aproveitadas na laminação de chapas grossas, foco deste trabalho.

A figura 4 mostra um exemplo de cálculo do modelo de mistura utilizado no lingotamento contínuo de placas de Ouro Branco.

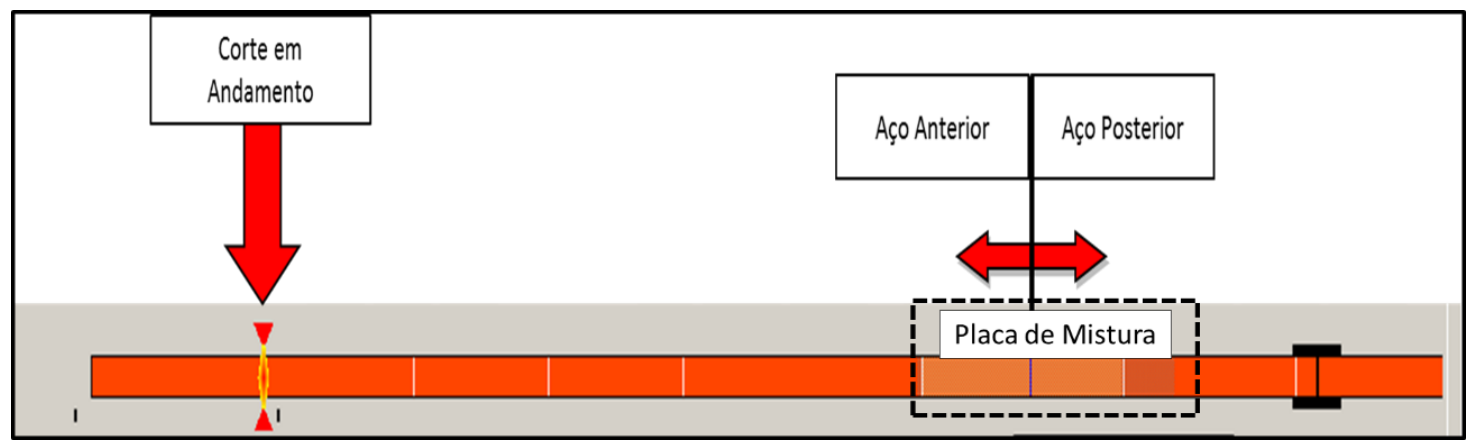

Figura 4. Exemplo de saída do modelo de transição de aços utilizado na Gerdau Ouro Branco.

A saída de dados do modelo matemático de mistura é apresentada através da concentração normal $[5,6]$ para o elemento químico controlador da mistura (chama-se neste trabalho de CF - fator de concentração) em função do comprimento da placa. A figura 5 representa um gráfico típico da variação de CF durante um procedimento de "mix steel" na Gerdau Ouro Branco.

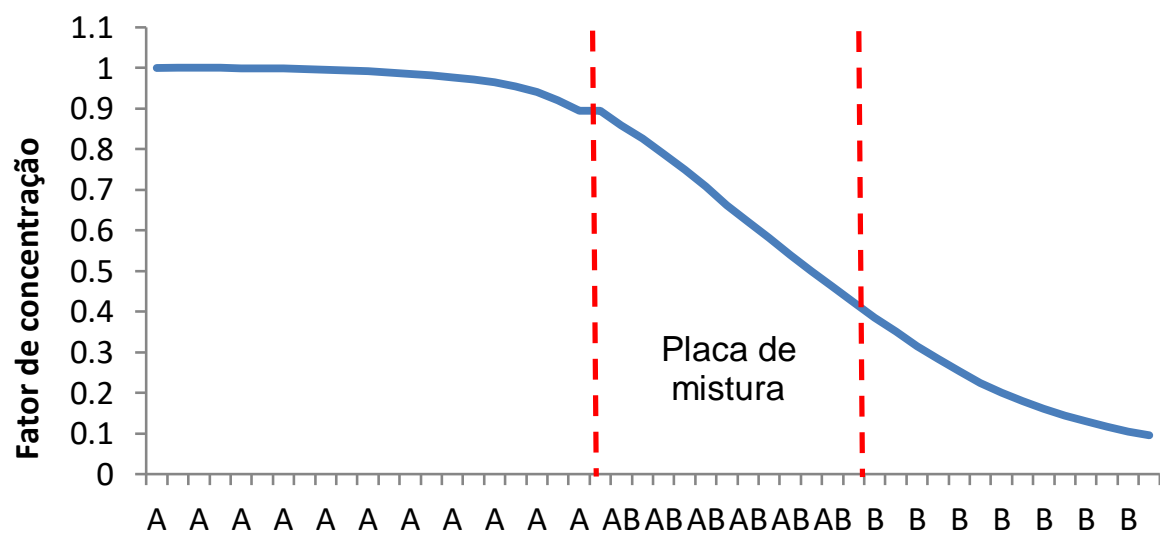

Tipo de aço

Figura 5. Gráfico do comportamento do valor de CF durante uma mistura de aço A para aço $\mathrm{B}$.

\section{MATERIAIS E MÉTODOS}

O aço selecionado para este estudo foi o grau ASTM A36 pois representa uma grande fração do volume de produção atual, contribuindo em grande parte pela perda por mistura na Aciaria, uma vez que são adotadas composições químicas diferentes em função da espessura final da chapa grossa.

Para a validação do modelo foram realizados procedimentos de mistura com estes aços considerando as variáveis similares: dimensão da placa (espessura e largura), peso de aço no distribuidor, taxa de enchimento do distribuidor e velocidade de lingotamento. 
Após o lingotamento, foram separadas as placas de mistura, realizados cortes longitudinais com $100 \mathrm{~mm}$ de espessura e retiradas amostras a cada um metro para a realização das análises químicas. A figura 6 ilustra um exemplo de placa de mistura analisada.

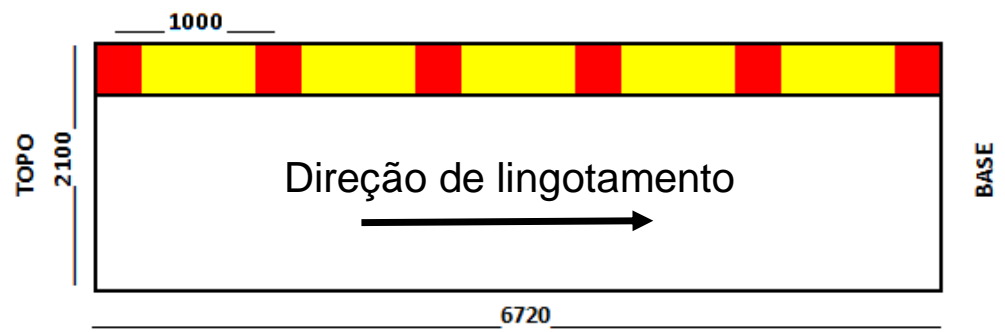

Figura 6. Exemplo de corte de amostras em uma placa de mistura.

A validação do modelo matemático se deu através da comparação entre os resultados previstos com os resultados obtidos nas análises químicas ao longo do comprimento da placa. Após esta etapa, foi possível verificar se existia ou não a necessidade de realizar ajustes nos cálculos do modelo para previsão do comprimento real da zona de mistura.

Depois de validado o modelo, algumas placas de mistura foram selecionadas para envio e laminação como produto chapa grossa. Para isso avaliou-se a composição química obtida e definiu-se qual seria a espessura final da chapa grossa a ser laminada. Antes de realizar a laminação, utilizou-se o modelo de previsão de propriedades mecânicas existente nessa laminação para verificar se a composição química ao longo do comprimento das placas de mistura atenderia à especificação dos produtos a serem laminados, neste caso para a norma ASTM A36. Após aprovadas as previsões deste modelo para os valores de LE (limite de escoamento) e LR(limite de resistência), as placas foram então laminadas e em seguida retiradas amostras para validação dos resultados de composição química e propriedades mecânicas.

A figura 7 mostra uma previsão de propriedades mecânicas de uma das placas de mistura laminada. 


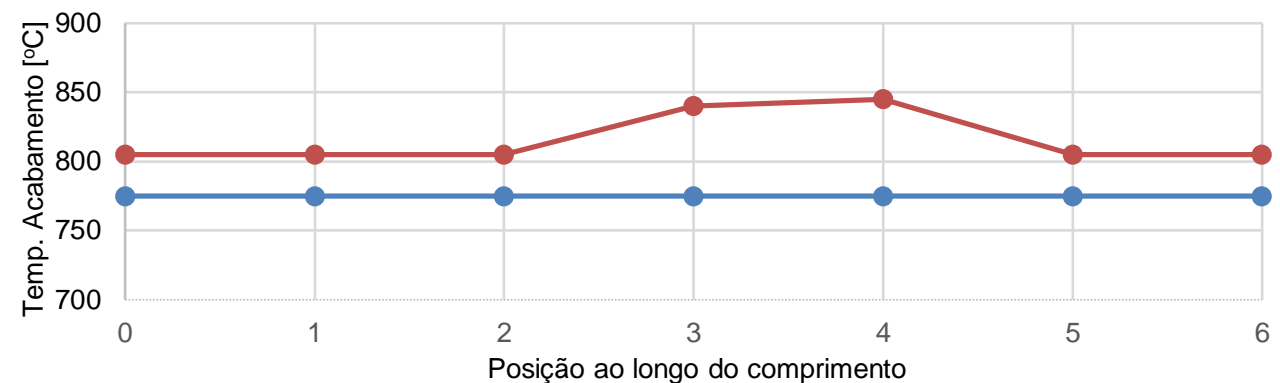

Posição ao longo do comprimento
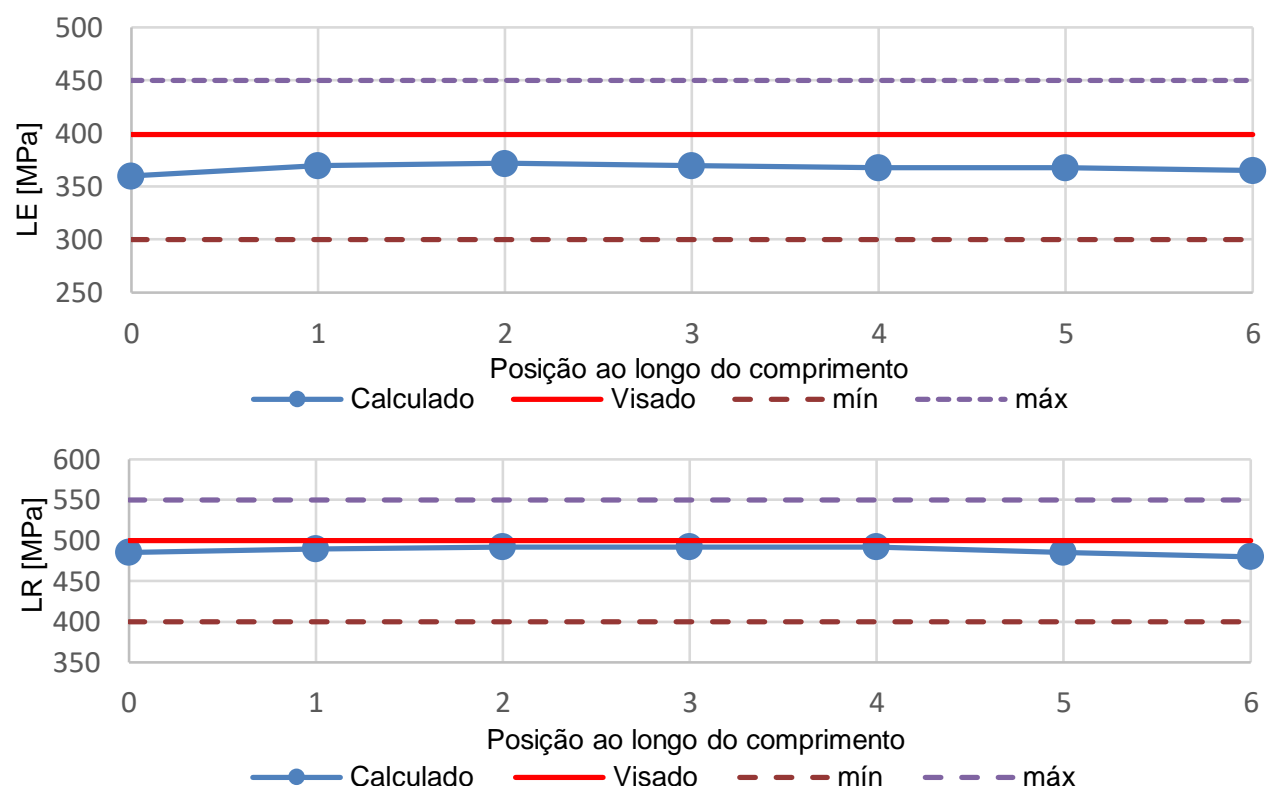

Figura 7. Exemplo de previsão do modelo de previsão de propriedades mecânicas para uma placa de mistura.

A figura 8 apresenta o método adotado para o corte das amostras de chapas grossas.
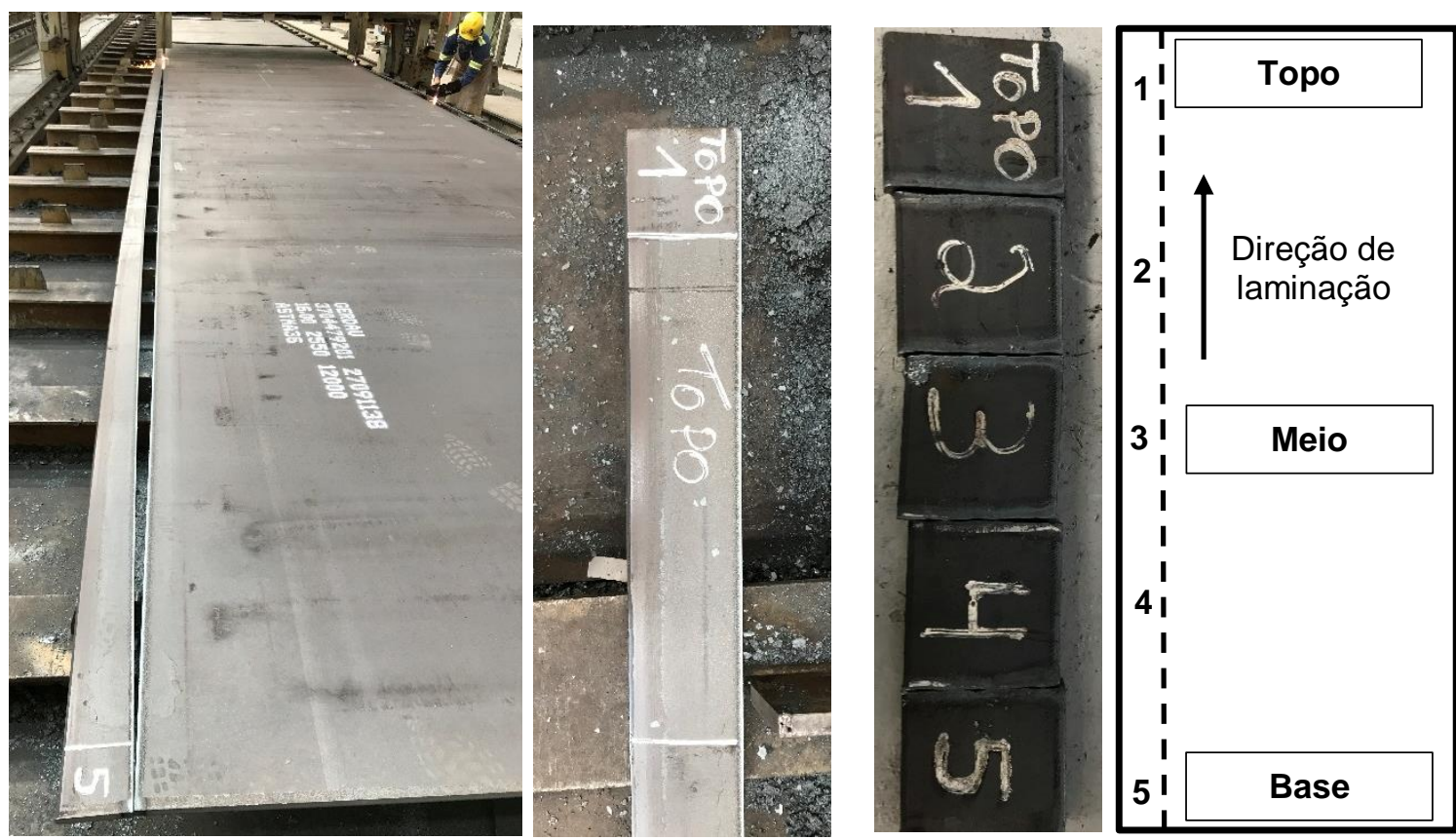

Figura 8. Retirada de amostras de uma chapa grossa analisada. 


\section{RESULTADOS E DISCUSSÃO}

Nesta etapa, serão apresentados os resultados comparativos entre o teor real do elemento químico analisado com o valor de CF calculados pelo modelo. Para essa comparação, os valores de composição química obtidos foram transformados em CF real. Essa comparação tem como objetivo validar o modelo matemático de mistura da máquina de lingotamento contínuo de placas, pois dessa forma é possível assegurar a qualidade do produto solidificado a ser enviado para a laminação. Posteriormente, haverá a comparação entre as amostras de composição química das chapas laminadas com o CF, com a finalidade de observar se a conformação do aço alterou a maneira com que aquele elemento químico controlador se distribui na peça. Por fim, serão apresentados gráficos que comprovarão a eficiência do modelo matemático da laminação de chapas grossas no que diz respeito à previsão de propriedades mecânicas do produto, LE e LR. Caso ocorra a validação dos dois modelos, há a clara possibilidade de aumentar o rendimento metálico sem comprometer a qualidade do produto laminado.

\subsection{Validação do modelo de mistura do lingotamento de placas}

Para validar o modelo de mistura, os dados de CF gerados pelo modelo foram confrontados com os dados das análises químicas reais das amostras retiradas das placas. Nessa etapa foram analisadas três placas de mistura (caso1, caso 2 e caso 3) similares com as previsões do modelo de mistura de aços. A figura 9 mostra essa comparação.

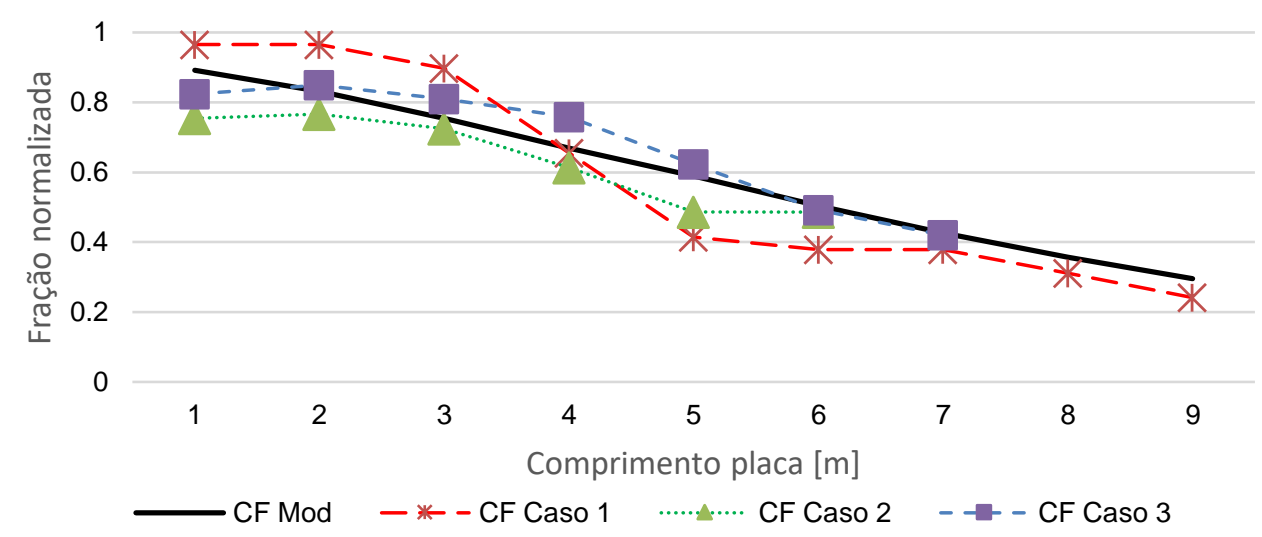

Figura 9. Comparação entre os dados reais das placas e os dados calculados pelo modelo.

Como os valores reais obtidos estão próximos dos valores calculados, o modelo é considerado válido para prever e definir a região de troca de aços para a placa lingotada, neste caso, não sendo necessário realizar ajustes nos cálculos de previsão. Assim, pode-se utilizar valores do modelo para decidir se a placa pode ou não ser aplicada para um determinado produto final.

\subsection{Comparação entre composição química da chapa com o valor calculado pelo modelo}

Nessa etapa foram retiradas amostras na borda das chapas para avaliação dos resultados de composição química, conforme mostrado na figura 8 . A figura 10 ilustra os valores de CF do modelo e os valores de CF para a composição química obtida em uma das peças laminadas, figura 10. 


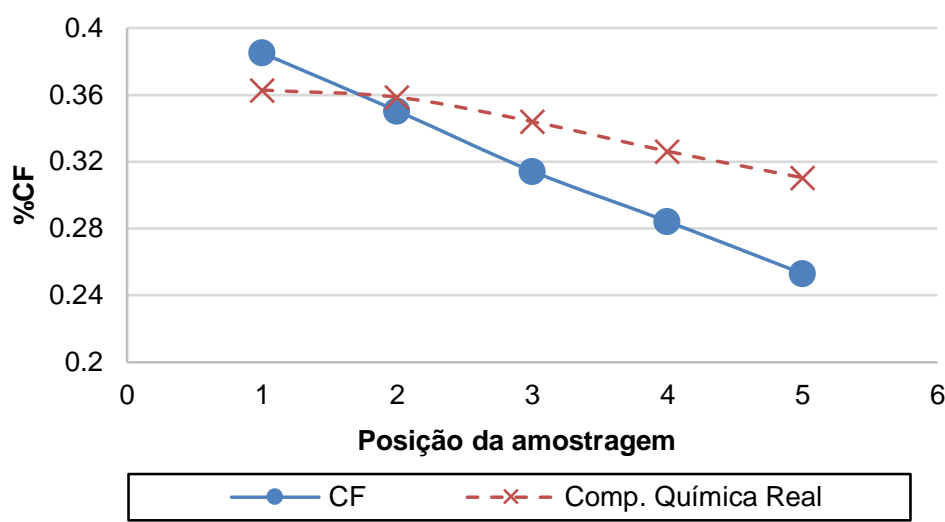

Figura 10. Comparação entre os resultados de composição química da chapa com os valores calculados pelo modelo de mistura.

Nota-se que existe uma pequena variação entre os valores encontrados e as previsões do modelo. Uma hipótese para justificar essa diferença é que o modelo de mistura do lingotamento não considera o efeito das variáveis de laminação que podem influenciar na concentração de algum elemento químico. Além disso, sabe-se que região amostrada na placa e na chapa não são exatamente a mesma, uma vez que o produto sofreu alargamento e alongamento.

O fato da composição química apresentar uma pequena variação tornou-se necessário comparar também os resultados de propriedades mecânicas.

\subsection{Comparação entre os valores de limite de escoamento e resistência do modelo de previsão de propriedades mecânicas com os valores reais}

A tabela 1 apresenta os resultados encontrados para as propriedades mecânicas (LE e LR) nos três casos estudados, bem como os valores previsto pelo modelo e pela norma do produto.

\begin{tabular}{|c|c|c|c|c|c|c|c|c|c|}
\hline \multirow{2}{*}{$\begin{array}{l}\text { Espessura } \\
{[\mathrm{mm}]}\end{array}$} & \multirow{2}{*}{ Posição } & \multirow{2}{*}{ Amostra } & \multicolumn{2}{|c|}{$\begin{array}{l}\text { Valor real } \\
\text { [Mpa] }\end{array}$} & \multicolumn{2}{|c|}{$\begin{array}{l}\text { Valor modelo } \\
\text { [MPa] }\end{array}$} & \multicolumn{3}{|c|}{$\begin{array}{c}\text { Norma ASTM A36 } \\
{[\mathrm{MPa}]}\end{array}$} \\
\hline & & & LE & LR & LE & LR & $\begin{array}{l}\text { LE } \\
\text { min. }\end{array}$ & $\begin{array}{l}\text { LR } \\
\text { min. }\end{array}$ & $\begin{array}{c}\text { LR } \\
\text { máx. }\end{array}$ \\
\hline \multirow{3}{*}{16,0} & 1 & Topo & 319 & 450 & 289,5 & 441,5 & 250 & 400 & 550 \\
\hline & 3 & Meio & 301 & 450 & 291,0 & 442,3 & 250 & 400 & 550 \\
\hline & 5 & Base & 294 & 445 & 289,5 & 441,5 & 250 & 400 & 550 \\
\hline \multirow{3}{*}{16,0} & 1 & Topo & 290 & 450 & 288,1 & 440,5 & 250 & 400 & 550 \\
\hline & 3 & Meio & 302 & 455 & 288,9 & 441,1 & 250 & 400 & 550 \\
\hline & 5 & Base & 295 & 453 & 287,7 & 440,2 & 250 & 400 & 550 \\
\hline \multirow{3}{*}{25,0} & 1 & Topo & 345 & 466 & 365,4 & 488,3 & 250 & 400 & 550 \\
\hline & 3 & Meio & 350 & 480 & 373,0 & 490,9 & 250 & 400 & 550 \\
\hline & 5 & Base & 349 & 472 & 372,2 & 489,9 & 250 & 400 & 550 \\
\hline
\end{tabular}

As figuras 11 e 12 apresentam os resultados para o limite de escoamento e resistência da chapa avaliada no caso 1 . Nota-se que ambos os resultados atenderam aos limites especificados pela norma ASTM A36. 


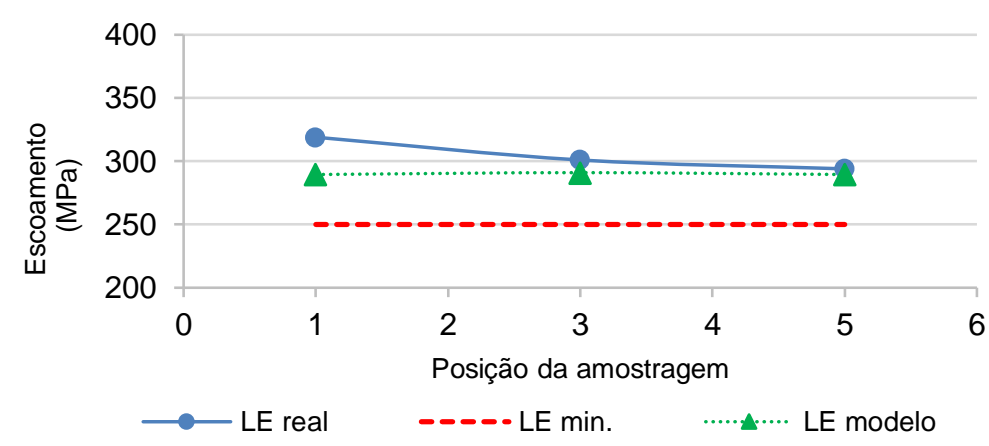

Figura 11. Comparação entre os resultados previstos e reais, caso 1, para o limite de escoamento.

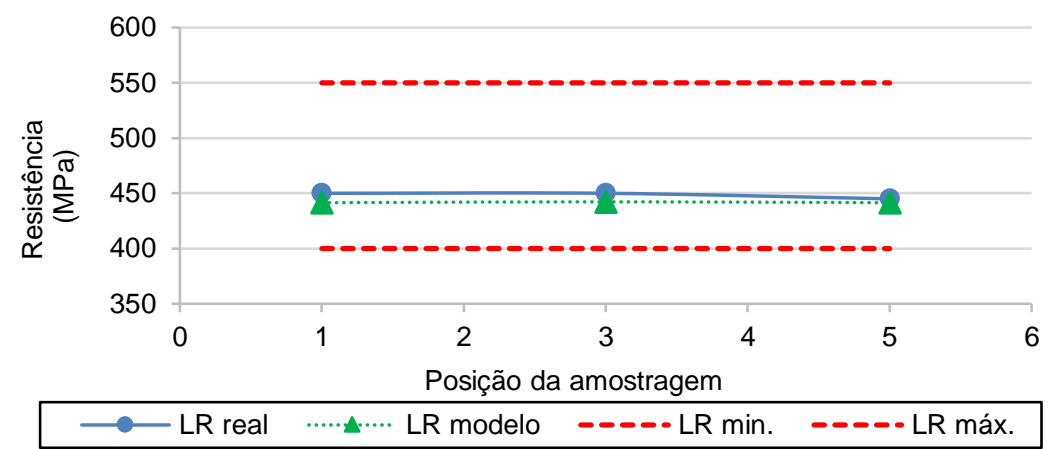

Figura 12. Comparação entre os resultados previstos e reais, caso 1, para o limite de resistência.

Analisando os resultados apresentados nas figuras 11 e 12 verifica-se que os resultados obtidos para o limite de escoamento e resistência estão similares aos previstos pelo modelo de previsibilidade de propriedades mecânicas. Além disso, as variações observadas no fator CF, figura 10, não resultaram em perda de propriedades mecânicas, uma vez que todas as três posições analisadas (topo, meio e base) atenderam aos limites estabelecidos pela norma, garantindo assim a aplicação final do produto na situação avaliada.

\section{CONCLUSÃO}

O modelo matemático adotado no lingotamento contínuo de placas da Gerdau Ouro Branco determina bem a transição de aços com composição química diferente, podendo ser utilizado para definir o comprimento da placa de mistura.

As previsões de propriedades mecânicas, limite de escoamento e resistência, do modelo existente na laminação de chapas grossas foram validadas pelos resultados obtidos na chapa avaliada do grau ASTM A36.

Pequenas variações de composição química na placa não resultam em variações significativas nos valores de limite de escoamento e resistência, deste que a chapa seja laminada para a espessura adequada e nas condições de laminação específicas para este produto.

O presente trabalho permitiu à Gerdau Ouro Branco reduzir as perdas por mistura de aços, uma vez que a correta aplicação destas placas permite o aproveitamento do produto laminado. Além disso, permitiu estabelecer um padrão de aplicação de placas de mistura para determinado produto, combinação entre espessura e propriedades mecânicas requeridas. 


\section{REFERÊNCIAS}

1 HUANG, X; ; THOMAS, B.G.; Intermixing Model of Continuous Casting during a Grade Transition Metallurgical Transaction B, v.27B, n. 4, p. 617-632, 1996.

2 ALIZADEH, M.; EDRIS, H.; PISHEVAR, A.R., Behavior of Mixed Grade during the Grade Transition for Different Conditions in the Slab Continuous Casting ISIJ International, v.48, n.1, p.28-37, 2008.

3 GOLDSCHMIT, M.B.; FERRO, S.P. Model for optimization of the grade transition in the round continuous casting, ECCOMAS, Barcelona, 2000.

4 WANG, H.; LI. G.; LEI. Y.; ZHAO. Y.; DAI. Q.; WANG1․ J.; Mathematical Heat Transfer Model Research for the Improvement of Continuous Casting Slab Temperature, ISIJ International, v.45, pp 1291-1296, 2005.

5 COSTA, A.M.; BARBOSA, F.A.; TAVARES, R.P. Modelagem matemática da transição de graus de aço lingotamento contínuo de placas, XXXV Seminário de Fusão, Refino e Solidificação dos Metais, ABM, Salvador, Brasil, 2004.

6 COSTA, A.M. Modelamento matemático da zona de mistura no lingotamento contínuo. Dissertação de Mestrado, Universidade Federal de Minas Gerais, Belo Horizonte, 2003. 